\title{
Young Rats and Negative Effects of Low-Alcohol and Energy Drinks
}

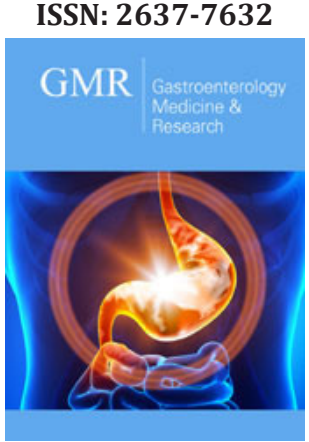

*Corresponding author: Trubitsyna IE, State budgetary institution of health care Moscow Clinical Scientific Center named after AS Loginova, Department of Health in Moscow, Russia

Submission: 觜 November 01, 2019

Published: 此 November 13, 2019

Volume 4 - Issue 1

How to cite this article: Trubitsyna IE, Fedotova TF, Mikhalev IV, Efremov LI, Degterev DA, et al. Young Rats and Negative Effects of Low-Alcohol and Energy Drinks. Gastro Med Res. 4(1). GMR.000576. 2019. DOI: 10.31031/GMR.2019.04.000576

Copyright@ Trubitsyna IE, This article is distributed under the terms of the Creative Commons Attribution 4.0 International License, which permits unrestricted use and redistribution provided that the original author and source are credited.

\author{
Trubitsyna IE*, Fedotova TF, Mikhalev IV, Efremov LI, Degterev DA, Kleschev \\ VN, Kleschev VV, Klescheva, Tarasova TV and Varvanina GG \\ Department of Health in Moscow, Russia
}

\begin{abstract}
Recently, low-alcohol and energy drinks have become widespread among young people, which are considered "harmless drinks "among them. However, young people get used to these drinks and cannot do without them, the dose of consumption increases. Therefore, it requires study to establish the role of the studied beverages in organizational and mental disorders. The article convincingly proves the causal relationship between alcohol and damage to internal organs and mental state in rats.
\end{abstract}

Keywords: Low-alcohol and energy drinks; Liver; Kidneys; Lungs; Heart; Psyche

\section{Introduction}

The behavior of any living creature is aimed at satisfying a particular need-biological, social. Need can be defined as an objective need for something, for this it must become subjective, normally perceived by the nervous system of the animal, and encourage him to act on its satisfaction, motivate both the animal and man to certain actions. In animals, the main biological motivations are food, drinking, sexual and self-preservation. The emergence of several motivations that require a choice, determine the highest priority. In animals, this is solved by an innate hierarchy of needs-the main one is self-preservation, which always prevails over the rest-when life is threatened, sexual, drinking or eating decreases. When drinking alcoholic beverages, the motivation for self-preservation is suppressed instantly and the craving for alcohol comes out in the first place, animals struggle for being at the drinker with an alcoholic beverage [1,2].

\section{Purpose}

To study the behavior of young rats in the use of low-alcohol (LA) and energy drinks (E).

\section{Material and Methods}

Studies were conducted on "young" white rats of the Wistar line, weighing 100-120g-1516 years by human standards. Three groups were identified: control (C)- animals had free access to water and food. Experimental groups $(0)-0^{1}$ animals had free access to water and food. Additionally, a drinking bow 1.) with E "Red Bull". 2.) was added, $\mathrm{O}^{2}$ - drinking bowl with LA "Black Russian" was added. Each group has 5 rats. Autopsy of animals after 14 and 45 days. The damage index (PI) is the number of injuries by the number of animals. In addition to animals, University teachers observed the behavior of young people (students) who used E and LA.

\section{Results and Discussion}

When observing the behavior of experimental animals, it was established that after 60minutes, the rats began to drink water, after 4-5 hours, the entire volume of the proposed drink was drunk- $350 \mathrm{ml}$. Control rats, during this time, drank $60 \mathrm{ml}$ of water. All the animals of $\mathrm{O}^{1}$ preferred e to water. In the future, they ate food $50 \%$ less. The water did not drink. Through 7 days persists preference $E$, but on $20 \%$ increased consumption feed and this raising persisted until the end of experiment. From the first day the behavior of animals changed, increased contact between animals, grooming. So, the first day there was activity and curiosity, after 72 hours the activity decreased, the rats became drowsy and apathetic. Continued to drink 
E drinks, feed consumption increased by $30 \%$. Communication of rats was limited to communication of individuals within a cage, "grouping" was created, and external stimuli did not distract them from each other. Being in a vertical stand took $20-30 \%$ of the time of observation of animals (8 hours), normally $10-15 \%$. An increase in the number of vertical uprights indicates an internal alarm. On day 10 reaction only when adding a new portion of the drink. The absence of E caused concern, the animals were near the drinking trough and waiting for a new portion (Figure 1).

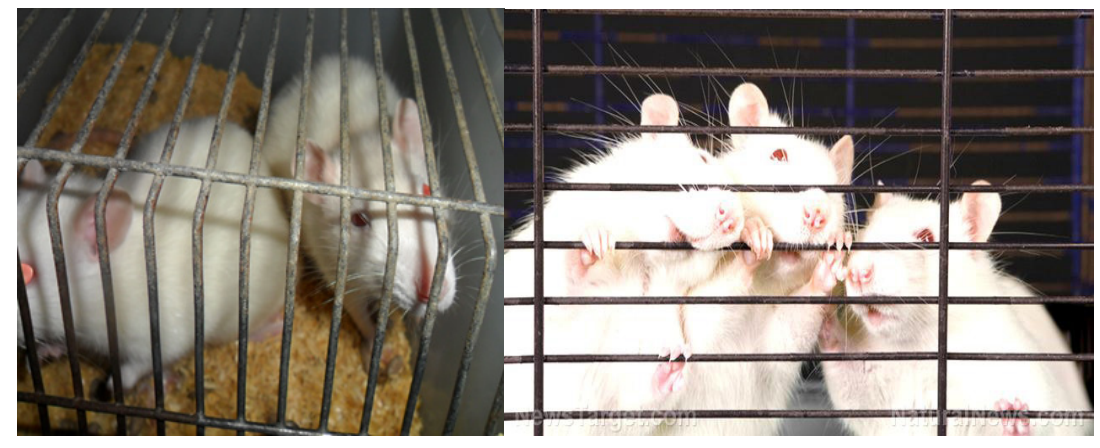

Figure 1: Rats waiting for a new portion.

LA-the effect of these cocktails is similar to the action of energy drinks, but the effect is faster and more pronounced. Through 20-30 minutes they already not departed from drinkers with LA. Dynamics behavior animals: in the first 60-90 minutes arousal, then drowsiness, expressed intoxicating effect, through 5-6 hours increased communication between animals, declined reaction on external stimuli, rats await only drink. Water consumption decreased by $10 \%$, food by $40-50 \%$. Animals are waiting every day they drank $350 \mathrm{ml}$ of the drink and demanded more. LA's absence caused anxiety and aggression. Aggression manifests itself even relative to employees, which daily fed animals, to which animals are accustomed. From the first hours They closed on communication within the "community" of animals, limited to the cell. Being in a vertical rack takes $30-40 \%$ of the time, normally $10-15 \%$. This demonstrates the presence of internal anxiety. On day 10, the external reaction only when adding a new portion of the drink. Low feed consumption is maintained. The lack of water is alarming; the animals are next to the drinker and waiting for a new portion. In this group there can be a fight. Rats wait for supplements, which drink, if you add them to the drinker. One rat from 4-' s unsupportable todrink water and there is fodder, and through 7 days it is died, Figure 3. The attraction to LA and E did not depend on the sex of the experimental animals $[3,4]$. The dependence on the age of rats is traced. After autopsy, it was found that young rats have lesions characteristic of old rats- pneumonia, dystrophy and hemorrhages in the myocardium, uneven blood filling of the myocardium uneven blood filling of the myocardium there are areas of weak blood filling alternating with foci of venous-capillary fullness. After that, the behavior of the animals changed while in the cage, a group of animals "closed in their circle", they almost did not respond to external irritation-the approach of employees to the cage or noise effects: voice, tapping on the cage. Communication between animals was active. They adopted a vertical stance, touching each other with their front paws, which was different from the usual behavior (they sleep during the day). There was an active reaction to the drinking bowl. On the morning on additive a new helpings drinks, in another time on removing this drinker, especially ranging with 3 -'s days use water.

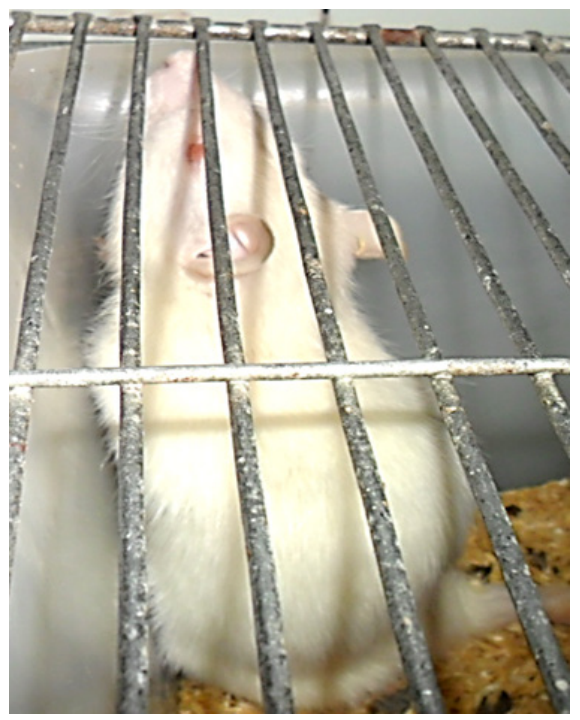

Figure 2: Rats are waiting for a soft drink low alcohol. 

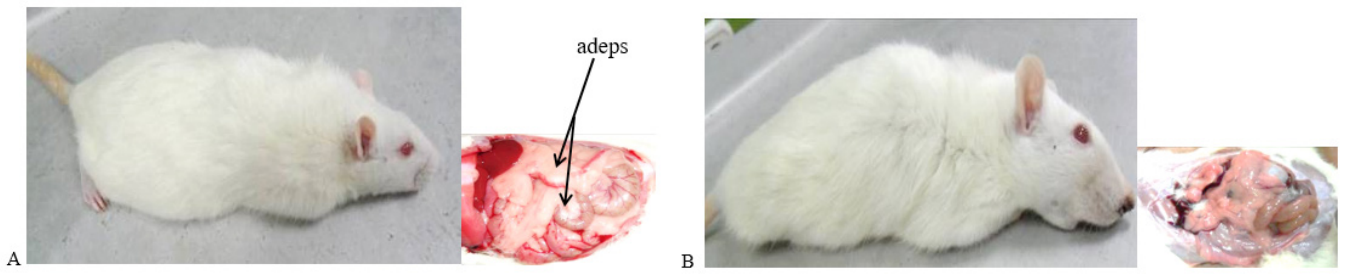

Figure 3: White rats, control weight bodies 200 propulsion A. after E mass bodies becomes 350g; after reception LA-120g.
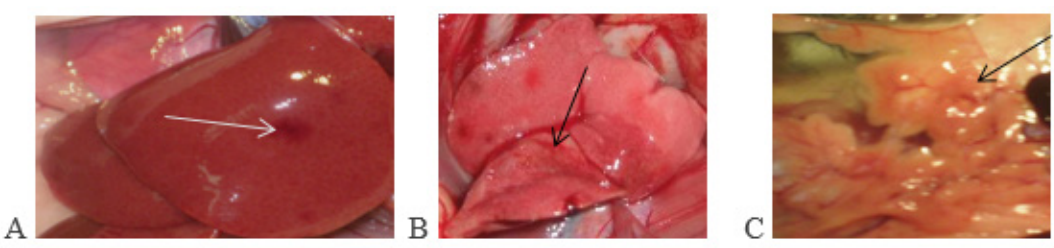

Figure 4: A. Liver closeup, subcapsular hemorrhage, B. Lungs, edema, hemorrhage, C. Pancreatic edema, enhanced vascular pattern. 14 days after using LAD.

Autopsy on day 14: -in the liver, subcapsular hemorrhage in each animal. Autopsy on day 45: "YOUNG" - starting from day 14, damages in the liver, lungs. pancreatic (Figure 3). Pneumonia in three rats, lungs - abscesses in two rats. Young rats quickly get used to it, increases tolerance to alcoholic beverages. In rats there is a habit and craving for an alcoholic beverage, the intoxicating effect occurs faster than at the beginning of drinking 45\% alcohol. There are diseases (pneumonia, myocardial damage) characteristic of older animals. Alcoholic myocardial damage (Figure 4 \& 5). All these changes occur faster and more pronounced in those animals that have previously drunk E, it is alarming that by LA and E there is a habit and a need to increase the dose of these drinks. Hierarchy of needs is changing, the instinct of self-preservation is practically no drinking or food craving, especially after LA. The survey of students is anonymous, the data were not disclosed. Students drink these drinks to increase the tone and ability to assimilate new educational material, but teachers note the opposite effect. A small temporary rise in tone (5-6 hours) was replaced by drowsiness and loss of strength. If a student consumed several cans of e, then memorization and assimilation of new skills decreased.
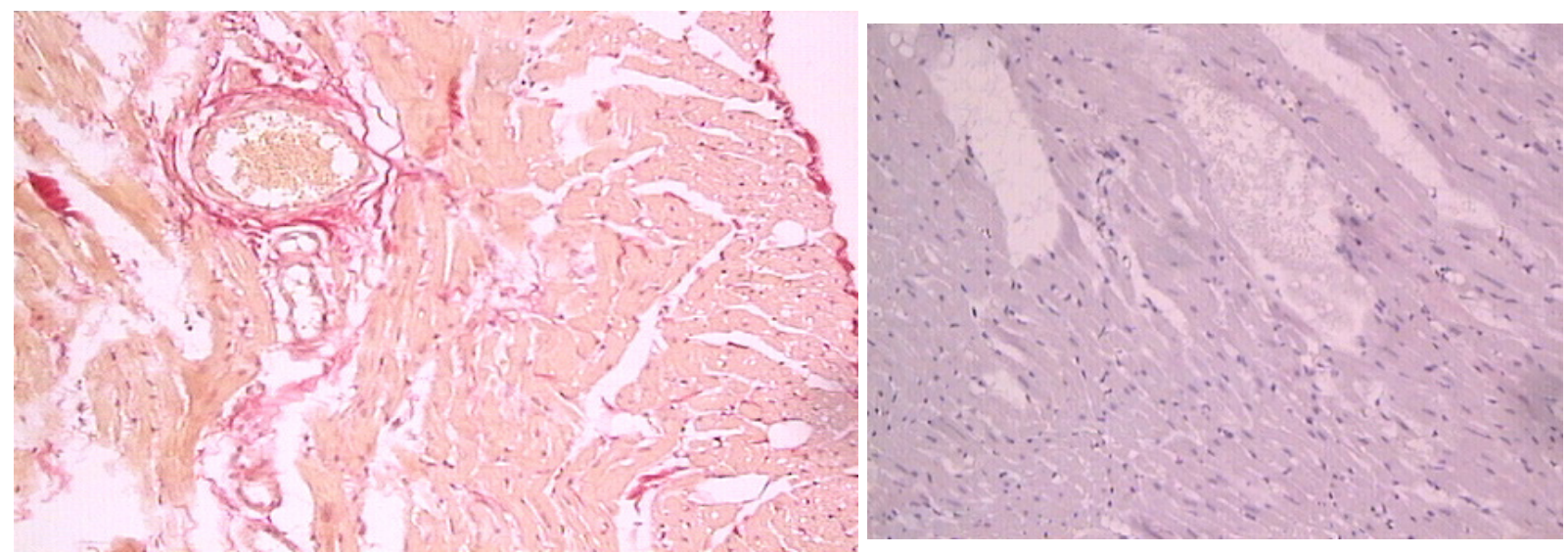

Figure 5: Rats. Microphotographs of the myocardium after LA (h\&e x160).

\section{Conclusion}

Young animals lose sense of self-restraint relative to LA and E. They drink all, that give and require still, in the absence of drinks emerges aggression to other animals and to service personnel. In young animals, the motivation for self-preservation is reduced. In the cell, groups of animals are created, showing interest in each other only within the group. In young animals, damage to the heart, lungs, kidneys, liver was noted, occurring only in old rats. Rejuvenation of chronic diseases. Reception of the studied drinks facilitates the transition to stronger alcoholic beverages (vodka), control animals do not drink vodka of any concentration. Observation of animals allows you to dispense drinks. We know the beginning of the use and could assess the behavior of animals for a long time period. Young people who used e did not have the effect that they expected, but there was an addiction to $\mathrm{E}$. We believe that we can translate the data obtained from animals to humans. 


\section{References}

1. Trubitsyna IE, Fedotova TF, Mikhalev IV, Efremov LI, Kleschev VN, et al. (2018) Alcohol-associated internal injuries in rats. Clin Exp Gastroenterol 6(154): 90-93.

2. Trubitsyna I, Fedotova T, Varvanina G (2019) Metabolic changes in violation in the system of neuro-endocrine regulation after consumption of energy and small-alcoholic beverages. " $2^{\text {nd }}$ World Congress on Gastroenterology \& Hepatology", London, UK, p.12.
3. Acheson A, MahlerSV, ChiH, DeWitH (2006) Differential effects of nicotine on alcohol consumption in men and women. Psychopharmacology (Berl) 186(1): 54-63.

4. Barrett SP, Tichauer M, Leyton M, Pihl RO (2006) Nicotine increases alcohol self-administration in non-dependent male smokers. Drug Alcohol Depend 81(2): 197-204.

For possible submissions Click below: 